not recollect to have seen any observations in British journals. We should welcome any communications on the penetration of eyelashes as a war injury.

\title{
Records of Visual Acuity
}

The Deputy Commissioner of the New York Department of Labour, part of whose work it is to determine the amount of compensation to be paid to claimants for losses in vision, writes to the American Journal of Ophthalmology pointing out that the scale he adopts is based 'upon such and such a percentage of loss.' If figures reach him as 20/20 he takes it that the man has 100 per cent. of vision; if $20 / 40$ that he has 50 per cent. of vision; and so on. He often receives reports from oculists, however, who do not work at a distance of twenty feet, and he then finds it most confusing to determine compensation on a percentage basis. $\mathrm{He}$ requests oculists in filling up the reports always to state specifically the percentage of loss of vision. In a note appended to the Deputy Commissioner's letter the Editor points out that the percentage scale has come into almost universal use in statistical studies. As applied to records of visual acuity it is easier to read and to print, and is indeed superior in all ways except that we are not accustomed to the method. "If the change made necessary the renumbering of our test-cards it would be an advantage, for they would be numbered more accurately."

\section{Eye Risks in Industrial Occupations}

In 1916, a survey of some seventy representative industries in the City of Buffalo was undertaken by the National Committee for the Prevention of Blindness (130, East Twenty-second Street, New York), and a book on "Eye Hazards in Industrial Occupations" has grown out of that inspection. An attempt has been made in the book to cover the entire field of risks to the eyes incurred in occupations in the United States, and a most interesting compilation is the result. The work bears the name as author of Gordon L. Berry, field secretary of the National Committee. Lieut. Thomas P. Bradshaw, U.S. Army, formerly technical assistant to the Director of the American Museum of Safety, has co-operated with $\mathrm{Mr}$. Berry. In the Buffalo examinations professional assistance was given by Drs. Ellice M. Alger (New York), Nelson M. Black (Milwaukee), Colman W. Cutler (New York), Francis E. Fronczek (Bufialo), Harold Giftord (Omaha), Franklin C. Gram (Buffalo), and F. Park Lewis (Bufialo). The contents of the book are extremely 
comprehensive, and among the other subjects dealt with we note accidents to the eye from intense heat and light radiations, and sections dealing with miners' nystagmus, poisoning by methyl alcohol (wood alcohol), and the lighting of shops and factories. As we hope, however, fully to review this timely publication in a later number of the Journal, we need in this place merely give readers some idea of the contents of a useful and meritorious production.

\section{OPHTHALMOLOGICAL SOCIETY OF THE UNITED KINGDOM.}

\section{Annual Congress, I9I8.}

THE Annual Congress of the Society was held on Thursday, Friday and Saturday, May 2nd to 4th, under the presidency of $\mathrm{Mr}$. E. Treacher Collins, and can be voted, especially in view of the Imperial position, a decided success; the meetings were well attended, and there was no diminution in the keenness of the debates. Papers were read and discussed, and the business meeting was held at the rooms of the Royal Society of Medicine, as well as a clinical meeting. A visit was paid to the Metropolitan Asylums Board Ophthalmia Schools at Swanley, where the President, who is also the responsible Medical Officer of the institution, entertained members to luncheon, and where a discussion took place on "Contagious Diseases of the Conjunctiva." The concluding event was a very interesting clinical meeting at the National Hospital for the Paralysed, Queen Square. On Thursday evening members dined together, and during the three days an Ophthalmological Museum was open for inspection, while an afternoon was devoted to a visit to the Royal College of Surgeons of England, where Colonel Lister, C.M.G., exhibited a number of instructive specimens.

The President, in the course of his opening address, said that although the public activity of the Society was now restricted to three days' proceedings, its activities were far from being confined to that period, for there were constantly arising matters of ophthalmological interest needing vigilance and care. Since the Report of the Committee appointed last year to deal with the standards of vision for the Army had been published, the medical examination of recruits had been transferred from the War Office to the Ministry of National Service, and the standard had been altered. He congratulated Colonel J. H. Parsons on having been appointed to the 